Tatiane Regina Pires de Araujo' Fernanda Lievore Polsin ${ }^{2}$
* Recebido em: 22/08/2015. Aprovado em: 23/03/2017.

1 Professora Doutora no curso de Administração do UniCEUB e na pós-graduação em Gestão de Pessoas e Coaching.

2 Psicóloga e especialista em Gestão de Pessoas e Coaching.

\section{Relação entre a interação familiar e a qualidade de vida no trabalho como provedora da satisfação para o colaborador*}

\section{Relationship between family interaction and quality of life at work as a provider of employee satisfaction}

\section{Resumo}

No mundo globalizado, prevalece a competitividade entre as empresas e entre seus funcionários. Como as famílias são constituídas por indivíduos imersos em uma realidade laboral, elas acabam sendo impactadas por tal contexto. Assim, o objetivo geral da pesquisa foi compreender a relação entre a interação familiar, a satisfação do colaborador e a qualidade de vida no trabalho. Para isso, foi realizada uma pesquisa bibliográfica na qual materiais já elaborados sobre os temas foram utilizados. Primeiramente, foi abordado o tema da família. Depois, a qualidade de vida no trabalho foi o foco. Após abordar os dois conceitos, um estudo sobre a interação entre eles tomou forma. As leituras possibilitaram uma análise sobre a relação entre a interação da família, a satisfação do colaborador e a qualidade de vida no trabalho. A mulher deixou de ter um papel, exclusivamente, familiar e começou a pleitear seu espaço no mercado de trabalho, ocorrendo, como consequência, um enriquecimento das atribuições domésticas do homem. Atualmente, existe um equilíbrio nessas responsabilidades. Assim, o que acontece em casa afeta o homem e a mulher que acabam por estender as questões domésticas aos seus ambientes laborais. Da mesma maneira, os dois podem carregar resquícios do trabalho para a família. Então, ficam claras a relação e a interferência mútua que existem entre a interação familiar e a qualidade de vida no trabalho, refletindo na satisfação do colaborador.

Palavras-chave: Qualidade de vida. Qualidade de vida no trabalho. Família. Satisfação.

\begin{abstract}
The world today as globalized, and prevails its employees competitiveness among companies and among in it. As families are constituted by individuals immersed in a labor reality, they end up being affected by such context. The objective of the research was to understand the relationship among family interaction, the employee satisfaction and the quality of work life. Therefore, we performed a literature search in which materials on these themes were used. First of all, we addressed the theme of family. Afterwards, the quality of work life was the focus. After addressing the two concepts, a study on the interaction among them took shape. The readings made possible an analysis of the relationship among the interaction of family, employee satisfaction and quality of work life. Woman no longer have an exclusively domestic role and began to claim a place in la-
\end{abstract}


bor market, leading to an enrichment of men's household duties. Nowadays, there is a balance in these responsibilities. Therefore, what happens at home affects men and women who end up extending their domestic issues to the working environments. Likewise, the both can carry work to home. So, the relationship and the mutual interference that exist among family interaction and quality of work life, reflecting on employee satisfaction.

Keywords: Quality of life. Quality of work life. Family. Satisfaction.

\section{Introdução}

O contexto competitivo do século XXI impera nas relações pessoais, comerciais e sociais. As famílias acabam sendo impactadas por esse contexto na medida em que são constituídas pelos indivíduos imersos nessa realidade. $\mathrm{O}$ ingresso da mulher no mercado de trabalho, a abertura do mercado econômico, as trocas culturais e outros aspectos pós-modernos resultaram em famílias cujas pessoas trabalham muito, com o intuito de melhorar sempre mais a condição financeira familiar.

Observa-se a incidência de uma espécie de supervalorização do trabalho. Os pais deixam suas casas, durante muitas horas do dia, para poder oferecer mais conforto aos filhos. Para isso, babás são contratadas ou as crianças precisam ir para creches/escolas muito cedo. Assim, as crianças passam a maior parte de seu tempo longe dos pais. Além disso, os cônjuges têm seu tempo de convivência reduzido. Ocorre uma reorganização da família, devido à inserção da mulher no mercado de trabalho e de sua responsabilidade como fonte de renda.

E é nessa dualidade, trabalho e família, que a pesquisa acontece, sempre pensando no tripé: qualidade de vida no trabalho, interação familiar e satisfação do colaborador. Tais temas estão, intimamente, relacionados e são emergentes no contexto pós-moderno.

É notório que o trabalho tem influência no lar, não só do brasileiro, mas dos cidadãos do mundo todo. E entender como qualidade de vida no trabalho e interação familiar se relacionam torna-se relevante para buscar a melhoria da qualidade de vida do colaborador. A questão principal da pesquisa é buscar entender: como ambiente familiar e contexto laboral podem impactar a qualidade de vida no trabalho dos colaboradores? Sendo assim, o objetivo geral da pesquisa foi compreender a relação en- tre a interação familiar, a satisfação do colaborador e a qualidade de vida no trabalho.

O pressuposto é a compreensão de que se o trabalhador não estiver adequado ao seu ambiente de trabalho, a família poderá ser prejudicada em algum sentido. Da mesma forma, se algo acontecer no seio familiar, o trabalho desse colaborador poderá ser afetado. Tendo isso em mente, os novos paradigmas da qualidade de vida no trabalho levam em consideração que as condições de crescimento na carreira não devem interferir na vida familiar do empregado (LIMONGI-FRANÇA; ARELLANO, 2002).

Para isso, faz-se necessário uma visão sistêmica capaz de abranger a totalidade. De forma que, para uma compreensão total do indivíduo, vale observar as dimensões presentes no sistema familiar em constante troca com o sistema organizacional, produzindo impactos em ambos e que pode resultar numa melhor qualidade de vida.

Para adotar uma visão de indivíduo concreto, é preciso considerá-lo mediado por seu grupo social e determinado histórica e socialmente. $\mathrm{O}$ homem não pode ser compreendido independentemente de suas relações e vínculos (AGUIAR, 2000). Dessa forma, não é possível falar de ser humano sem mencionar sua família, seu contexto familiar e a influência entre os temas.

O estudo em questão foi elaborado por meio de pesquisa bibliográfica em materiais já desenvolvidos sobre os temas: família e qualidade de vida no trabalho. Foi realizada uma abordagem sobre sua interação, possibilitando, finalmente, uma análise com o foco na relação entre a interação da família, a satisfação do colaborador e a qualidade de vida no trabalho.

\section{Método}

O modelo adotado para a realização da pesquisa foi qualitativo, já que esse tipo de pesquisa costuma ser direcionado e não procura medir ou enumerar fatos. De forma geral, instrumentos estatísticos não são utilizados para a análise de dados e o foco de interesse é ampliado (NEVES, 1996).

As pesquisas do tipo exploratória fazem parte do modelo qualitativo. Elas têm como finalidade proporcionar maior intimidade e familiaridade com o problema, visando construir hipóteses e torná-lo mais explícito. $\mathrm{O}$ planejamento costuma ser flexível, porque considera os 
aspectos mais variados relativos ao fato estudado. A coleta dos dados pode acontecer de diferentes formas, mas, de maneira geral, abarca o levantamento bibliográfico; Entrevistas com pessoas que tiveram experiência prática com o assunto; Análise de exemplos que estimulem a compreensão (GIL, 2010).

O levantamento bibliográfico foi escolhido para a realização da pesquisa. Ele é desenvolvido com base em materiais já elaborados, principalmente, aqueles encontrados em livros e artigos científicos. Sua principal vantagem está no fato de permitir que se tenha maior conhecimento dos fenômenos (GIL, 2010).

Os livros e artigos científicos utilizados para a realização da pesquisa foram escolhidos por sites de busca e bibliotecas digitais. Ao entrar em contato com a bibliografia, os critérios para a escolha do material a ser utilizado para a pesquisa foram: a indicação da orientadora, a abordagem dos temas família e qualidade de vida no trabalho e aqueles que apresentaram maior clareza sobre os conceitos.

\section{Qualidade de vida no trabalho e família}

$\mathrm{O}$ artigo traz temas que estão intrinsecamente relacionados: a família, a qualidade de vida no trabalho e seus impactos para o bom desempenho do colaborador. E, para buscar entender como tais temas se relacionam, é importante estudá-los, separadamente, para, posteriormente, compreendê-los em conjunto, influenciando na satisfação do trabalhador.

\subsection{A família}

Para uma melhor compreensão do seu conceito, será utilizada, inicialmente, a compreensão de que família é uma forma especial de sistema, possuindo propriedades, padrões e estrutura. Propriedades são as responsáveis por organizar mudança e estabilidade. Padrões, por sua vez, são os que definem os caminhos que a família usa para controlar as atitudes de seus membros e tomar suas decisões. Finalmente, estruturas são padrões de influências previsíveis e recorrentes que refletem hierarquias, tensões e filiações. (MINUCHIN; FISHMAN, 1990).

Para Minuchin e Fishman (1990), a família deve ter uma estrutura para cumprir seus papéis e dar apoio para a individuação de seus membros, ao mesmo tempo que promove um sentido de pertencer.
[...] Ela proporciona a construção de nossa primeira identidade e nos insere nas relações sociais, tanto em nível emocional, cultural, como socioeconômico. A 'família' é o primeiro referencial e permeia toda a nossa existência (JOSÉ FILHO, 1998, p. 15).

A família é um grupo natural que desenvolve modelos de interação que compõem sua estrutura e que governam seu funcionamento. Tal estrutura promove a viabilidade do sistema pautando-se em suas funções de suporte para a individualização e de desenvolvimento do sentido de pertencer à família (MINUCHIN; FISHMAN, 1990).

Ainda segundo Minuchin (1982), a família desenvolve um conjunto de papéis essenciais para o crescimento do ser humano que enfrenta variadas tarefas em prol de seu desenvolvimento. Trata-se de uma organização de apoio, proteção, limites e socialização de seus integrantes. É preciso, ainda, conviver com as mudanças de valores, de padrões éticos, políticos, econômicos e ideológicos, para, assim, acompanhar as modificações sociais e garantir a manutenção da estabilidade.

A família brasileira sofreu mudanças ao longo da história. Inicialmente, coerente com o tipo de colonização desenvolvido pela coroa portuguesa, para a Terra de Vera Cruz vieram o branco europeu - para explorar as riquezas da nova colônia - e o negro africano - para o trabalho escravo. Juntamente ao índio nativo, teve início a miscigenação, que influenciou, decisivamente, a formação da sociedade brasileira.

A mudança da corte portuguesa para o Brasil trouxe, também, diversas famílias tradicionais que deram novo formato à sociedade colonial. Os movimentos abolicionistas da metade do século XIX acabaram por modificar o tipo de imigração, levando um grande número de europeus a ingressar no Brasil, para exercer ofícios antes realizados pelos escravos. Em decorrência disso, aumentou, ainda mais, a miscigenação, graças ao incremento no número de casamentos entre pessoas de diferentes origens.

Tal miscigenação, as diferenças socioeconômicas, a magnitude do território nacional e a diversidade de modelos familiares tornam difícil uma generalização da família brasileira.

Além disso, a vida moderna apresenta novas configurações para a família nuclear (pais e filhos). São famílias formadas por pais separados, pais recasados, mães ou pais solteiros, entre outros casos. Entretanto, "a família nunca deixou de constituir-se numa rede de sustentação afetiva básica sobre o qual se fundamenta a segurança 
psicológica para formação e crescimento de cada geração nova de filhos" (BERTOLINI, 2002, p. 24).

Dados do IBGE (2006) apontam significativas mudanças na família brasileira. Para ilustrar tais mudanças, apresenta-se o percentual das famílias formadas por casais com filhos, que diminuiu de $56,6 \%$ para $48,5 \%$, na Região Sudeste, entre 1995 e 2005.

Alguns estudos sobre a família brasileira enfatizam quatro fatores para as mudanças ocorridas ao longo do tempo:

As exigências econômicas decorrentes da intensificação industrial e urbana;

A inserção profissional da mulher;

A distribuição social do conhecimento pela transformação súbita nos meios de comunicação de massa;

A quebra do poder integrador das relações de parentesco com o enfraquecimento da família nuclear (BENINCÁ; GOMES, 1998).

Estudos já realizados assinalam a importância dos cuidados dos pais para que seja possível garantir condições mínimas para um desenvolvimento saudável de seres humanos independentes, bem-sucedidos e socialmente integrados.

A família é uma célula modificável, que transforma e é transformada pela sociedade como um todo. Ela permite mudanças sociais pelas regras conceituais e comunicativas. Pelo caminho inverso, a "organicidade familiar" (BENINCÁ; GOMES, 1998, p. 178) se redimensiona em decorrência das pressões sociais que surgem por tais mudanças. Trata-se de uma movimentação constante de oposição entre os valores e regras da herança familiar e os valores e regras da atualidade.

A dinâmica relacional da família, no processo de socialização, está submetida às leis internas e externas. Leis internas, para Benincá e Gomes (1998), são as regras da própria família, e leis externas, aquelas em virtude do contexto social vigente no qual a organização familiar se encontra.

A família tem funções e atribuições indispensáveis para a humanização de seus membros, sem importar a estrutura que possa adquirir. Os seres humanos nascem no seio das famílias. Todos têm um pai, uma mãe e, algumas vezes, irmãos. É pela ação humanizadora da família que o indivíduo se torna humano. Os aspectos emocionais intra e intersubjetivos se evidenciam na família. É nela que os indivíduos aprendem, vivenciam e experimentam os modelos que servirão de modelo para as outras relações que desenvolverão durante sua vida.
Uma vez constituída, a família permanece. Essa permanência se traduz no tempo (GONÇALVES, 2002).

Essas mudanças na família brasileira ocorreram em consonância com a modificação no papel de homens e mulheres. Até os dias de hoje, o papel da mulher na sociedade foi se transformando, ampliando e diversificando. Seu campo de atuação vem crescendo até os dias atuais.

No início do século XX, o espaço social da mulher era limitado ao círculo familiar.

A partir da década de 40 , a mulher começou sua entrada no mercado de trabalho, com função principal de professora primária.

O fluxo migratório, antes e depois da Segunda Guerra Mundial, contribuiu para a assimilação de novos hábitos.

Aos poucos, a mulher foi ingressando no âmbito acadêmico (BERTOLINI, 2002).

A mulher busca, ao mesmo tempo, realização profissional e pessoal. Ela tenta preservar seu papel como mãe e, aliado a isso, demonstra desejo pela independência econômica. Por mais que a integração desses novos papéis seja conflituosa, a construção da nova identidade é fonte de status e poder.

Ela passa a investir mais tempo em sua formação acadêmica e profissional. Com isso, o casamento passa a ser adiado e não é mais prioridade na vida de muitas mulheres. Além disso, com o avanço da medicina, houve uma melhoria nos métodos contraceptivos, o que acarretou uma diminuição do número de filhos por casal.

O papel do homem, também, foi se modificando ao longo do tempo.

No começo do século XX, o homem era considerado detentor do poder. Ele era o responsável pelo sucesso profissional, financeiro e pelo sustento da família.

Com o avanço do poder econômico da mulher, o poder absoluto que o homem tinha sobre as decisões da família foi perdendo espaço.

Também pela modificação do papel da mulher, o homem passou a ser cobrado quanto ao companheirismo, quanto à participação na vida doméstica e quanto à atenção afetiva e sexual devida à esposa.

Pode-se considerar que o homem perdeu espaço, entretanto, houve uma ampliação e um enriquecimento de seu papel (BERTOLINI, 2002).

As famílias se modificaram até os dias de hoje, assim como os homens e as mulheres que as formam. Como 
consequência, as crianças também crescem com uma visão de mundo diferente daquela dos seus pais e avós.

Em resposta aos aspectos dessa realidade contemporânea, as famílias buscam uma forma de dividir as tarefas, pais e mães compartilham tarefas educativas e operacionais do dia a dia da família. A dinâmica de cada um possuir sua responsabilidade específica vai se diluindo nesse processo de divisão (ARAÚJO, 2011).

Dessa forma, a maneira de se visualizar a qualidade de vida no trabalho mudou. Então, para entender a família e sua relação com o desempenho do colaborador e a qualidade de vida no trabalho, é necessário conhecer como essa foi se modificando até chegar aos dias atuais.

\subsection{Qualidade de vida no trabalho}

Tendo sido abordado o tema "família", torna-se oportuno explorar o tema "qualidade de vida". Para melhor compreender a relação entre a interação familiar, a satisfação do colaborador e a qualidade de vida no trabalho, é preciso entender como esta passou a ser importante para as organizações.

O departamento de Gestão de Pessoas (GP) tem como função gerenciar a cooperação dos indivíduos que atuam nas organizações para que os objetivos individuais e os organizacionais sejam alcançados. Tal departamento constitui uma evolução das áreas de administração de pessoal, relações industriais e administração de recursos humanos. É ele o responsável, na maioria das organizações, pela gestão da qualidade de vida no trabalho.

O termo Gestão de Pessoas aparece, ao final do século XX, como similar para gestão de talentos, gestão de parceiros e gestão do capital humano, conceitos que estão se popularizando. Chiavenato (apud GIL, 2001) afirma que as pessoas constituem o capital intelectual das organizações e, por isso, devem ser tratadas como parceiros.

Quando as organizações se tornam bem-sucedidas, tendem a crescer. Dessa forma, os recursos necessários para que suas atividades sejam executadas tornam-se mais complexos. Aumenta-se o capital, incrementa-se a tecnologia, cresce o número de colaboradores e existe maior necessidade de intensificar a aplicação de seus conhecimentos e habilidades. É necessário que os recursos sejam utilizados com eficiência e eficácia. Nesse modelo, as pessoas significam o diferencial competitivo que mantém e promove o sucesso da organização (CHIAVENATO, 2004).

As empresas precisaram mudar seus conceitos e alterar suas práticas gerenciais. Assim, passaram a investir mais nas pessoas. Fala-se em estratégias de recursos humanos para indicar a utilização das pessoas no auxílio de manter ou ganhar vantagem no mercado de trabalho.

Sempre existiu a preocupação com melhores condições de trabalho. Nos anos 50, as relações indivíduas versus trabalho versus organização começaram a ser estudadas, e, segundo Rodrigues (ARAÚJO, 2010), essa nova forma de pensar recebeu o nome de qualidade de vida no trabalho ou QVT. Entretanto, apenas na década de 70, o termo foi exposto publicamente pelo professor Louis Davis, de Los Angeles.

Ainda no início dos anos 70, os estudos de QVT passaram por um período de estagnação, devido à conjuntura mundial. As técnicas de gestão passaram a ser o foco das organizações, deixando os estudos sobre qualidade de vida no trabalho à margem das discussões até o final da década.

Por certo tempo, quando o tema qualidade nas empresas era abordado, a produção tinha muita ênfase. Nos dias atuais, não apenas a qualidade no trabalho é pontuada, mas também a qualidade de vida dos empregados (GIL, 2001).

A qualidade de vida no trabalho aparece criando oportunidades para o trabalhador, fazendo que ele tenha maior responsabilidade e autonomia, participação no processo decisório, nos resultados e no seu próprio desenvolvimento, tanto pessoal quanto profissional. Dessa forma, o colaborador tem maior oportunidade de realização pessoal e progresso no âmbito laboral.

\subsubsection{Concepções evolutivas do QVT e suas caracte- rísticas}

QVT como uma variável (1959 a 1972): reação do indivíduo ao trabalho. Era investigado como melhorar a qualidade de vida no trabalho para o indivíduo.

QVT como uma abordagem (1969 a 1974): o foco era o indivíduo antes do resultado organizacional; mas, ao mesmo tempo, tendia a trazer melhorias tanto ao empregado quanto à direção.

QVT como um método (1972 a 1975): um conjunto de abordagens, métodos ou técnicas para melhorar o ambiente de trabalho e tornar o trabalho mais produtivo e mais satisfatório. QVT era visto como sinônimo de grupos autônomos de trabalho, enriquecimento de cargo ou desenho de novas plantas com integração social e técnica.

QVT como um movimento (1975 a 1980): decla- 
ração ideológica sobre a natureza do trabalho e as relações dos trabalhadores com a organização. Os termos administração participativa e democracia industrial eram, frequentemente, ditos como ideais do movimento de QVT.

QVT como tudo (1979 a 1982): como panaceia contra a competição estrangeira, problemas de qualidade, baixas taxas de produtividade, problemas de queixas e outros problemas organizacionais.

QVT como nada: no caso de alguns projetos de QVT fracassarem no futuro, não passarão de apenas um "modismo" passageiro. Fonte: Nadler \& Lawler (apud FERNANDES, 1996, p. 42).

O termo qualidade de vida no trabalho possui diversas abordagens. É um tema bastante debatido e pesquisado, cuja conceituação varia conforme os elementos que se julgam ser mais relevantes para que haja, efetivamente, qualidade de vida no trabalho (ARAÚJO, 2010).

Para Limongi-França e Arellano (2002), qualidade de vida no trabalho (QVT) é o conjunto de ações de uma organização com o intuito de implementar melhorias e inovações gerenciais, tecnológicas e estruturais no ambiente de trabalho. Entretanto, existem várias interpretações sobre QVT.

Pode significar desde a ausência de doenças no âmbito pessoal até as exigências de recursos, objetivos e procedimentos de ordem gerencial e estratégica no nível das organizações (LIMONGI-FRANÇA; ARELLANO, 2002).

Para Walton (1974 apud FERNANDES, 1996), QVT é utilizada para designar experiências inovadoras realizadas na busca de resgatar valores, tanto ambientais quanto humanísticos, que foram negligenciados pela sociedade industrializada em prol do aumento da tecnologia e do crescimento da economia, tendo como pontos básicos condições de trabalho melhores e produtividade.

Ainda segundo Walton (1973 apud FERNANDES, 1996), um programa de QVT deve promover uma organização mais humanizada. Envolvendo, ao mesmo tempo, responsabilidade e autonomia em cada cargo, feedback sobre o desempenho do colaborador, tarefas apropriadas para um enriquecimento do trabalho, além da ênfase no desenvolvimento pessoal de cada colaborador.

Novos paradigmas sobre formas de vida, tanto dentro quanto fora da empresa, que constroem novos valores relativos às questões de QVT, estão sendo estruturados por vários segmentos. Alguns exemplos são:
A saúde, que tem como objetivo preservar a integridade física, psicológica e social do ser humano, em vez de agir apenas para controle de doenças e para propiciar maior expectativa de vida e reintegração profissional da pessoa que ficou doente.

A psicologia, que afirma que as atitudes internas e as perspectivas de vida da pessoa são importantes, além do significado intrínseco das necessidades do indivíduo para seu envolvimento com o trabalho.

A sociologia, que age sobre a dimensão simbólica daquilo que é compartilhado e estabelecido socialmente, demonstrando as implicações daqueles que influenciam ou são influenciados nos vários contextos culturais e antropológicos da organização (LIMONGI-FRANÇA; ARELLANO, 2002).

Deve existir, dentro da empresa, um ambiente favorável para as relações pessoais. Tal ambiente é alcançado com democracia social, união, companheirismo, comunicação aberta e ausência de preconceitos.

A atuação social da organização significa muito para os empregados, tanto na percepção que eles possuem da empresa quanto em sua autoestima (LIMONGI-FRANÇA; ARELLANO, 2002).

Importância do programa de QVT:

Satisfação no âmbito laboral, impulsionando a autoestima dos colaboradores e contribuindo para que indicadores negativos (absenteísmo, doenças do trabalho, acidentes e aposentadorias precoces) sejam reduzidos.

Aumento da efetividade da organização, contribuindo para a redução dos indicadores negativos (erros, retrabalho, queda de produtividade, perda de qualidade nos serviços prestados, perda de material, danificação de equipamentos) (MENDES, 2006)

\subsubsection{Modelo de Walton para aferição da qualidade de vida no trabalho}

Compensação justa e adequada: faz referência à satisfação do trabalhador por sua remuneração quando comparada interna e externamente.

Renda adequada ao trabalho: salário justo pelas tarefas que desenvolve.

Equidade interna: verificar se existe diferença entre remuneração dos trabalhadores que executam as mesmas tarefas dentro da organização.Equidade externa: verificar se a remuneração de um trabalhador de outra organização, de igual porte e setor, é parecida ou igual à remuneração dos empregados da organização pesquisada, quando executam tarefas semelhantes. 
Condição de trabalho: a satisfação do trabalhador está relacionada a horários razoáveis, condições de trabalho que reduzam riscos de doenças e danos físicos ou a determinação de limites de idade.

Jornada de trabalho: a carga horária das funções desenvolvidas na organização corresponde àquela descrita na legislação vigente.

Ambiente físico seguro e saudável: a organização deve acatar as normas de segurança, fornece equipamento de proteção e buscar minimizar acidentes de trabalho, zelando pela integridade dos trabalhadores e, como consequência, pela saúde e qualidade de vida de cada um.

Oportunidade de uso e desenvolvimento de capacidades: faz referência à possibilidade de o trabalhador utilizar suas competências e seus conhecimentos, desenvolvendo autonomia.

Autonomia: a organização consente que o colaborador tenha certo limite para resolver determinados problemas relacionados a suas tarefas.

Significado da tarefa: o trabalhador se realiza com as atividades que desempenha.

Identidade da tarefa: a organização mede o grau de satisfação de seu colaborador em relação ao trabalho.

Variedade da habilidade: a tarefa não é repetitiva, exigindo diferentes conhecimentos e habilidades, o que torna o trabalho mais dinâmico.

Retroinformação: a organização concede ao empregado informações sobre seu desempenho.

Oportunidade de crescimento e segurança: a oportunidade de carreira é o foco, bem como as dificuldades que o trabalhador enfrenta.

Possibilidade de carreira: um plano de cargos e salários deve existir para que os trabalhadores habilitados tenham a possibilidade de ascensão profissional.

Crescimento profissional: a organização proporciona a seus colaboradores a oportunidade de adquirir e aperfeiçoar conhecimentos por meio de um plano de desenvolvimento e capacitação.

Segurança de emprego: a empresa possui uma adequada estrutura de Recursos Humanos, que promove um sentimento de segurança em relação ao cargo.

Integração social no trabalho: as relações interpessoais são importantes para verificar o nível de identidade dos trabalhadores com a organização. Como consequência, o grau de satisfação deles com a qualidade de vida no trabalho.

Igualdade de oportunidade: trata-se da ausência de preferência entre os colaboradores. Os trabalhadores devem sempre passar por uma seleção para que possam ser promovidos, transferidos ou admitidos.

Relacionamento: procura-se que haja um bom relacionamento interpessoal e espírito de equipe no âmbito laboral.

Constitucionalismo: tal fator, essencial para garantir a qualidade de vida no trabalho, está embasado nos direitos e deveres dos trabalhadores.

Respeito às leis e direitos trabalhistas: a organização deve estar atenta e cumprir todos os direitos dos trabalhadores que estiverem previstos por lei.

Privacidade pessoal: a empresa deve respeitar a privacidade de seus colaboradores, sempre que suas atitudes não interfiram em assuntos do trabalho.

Liberdade de expressão: os superiores hierárquicos devem estar abertos a ouvir sugestões e ideias de seus funcionários.

Normas e rotinas: normas e costumes da empresa devem estar claros, definidos, entendidos e aceitos por todos.

Trabalho e espaço total da vida: Experiências no âmbito laboral podem interferir na vida pessoal e social dos trabalhadores, tanto positiva como negativamente. É recomendado que se procure um equilíbrio. É necessário que se verifique o nível de satisfação dos colaboradores em relação à influência que o trabalho exerce em sua vida privada, avaliada por meio da opinião sobre a estabilidade de horários, mudanças, balanceamento da jornada, entre outros assuntos que comprometem a disponibilidade de tempo para a família.

Papel balanceado do trabalho: o colaborador deve ter um equilíbrio satisfatório entre seu trabalho e as outras atividades existentes em sua vida.

Relevância social da vida no trabalho: algumas empresas agem de forma irresponsável, o que faz com que seu colaborador deprecie o trabalho, afetando, assim, sua auto-estima e, como consequência, sua produtividade.

a) Imagem da empresa: é fundamental que a organização conserve excelente imagem perante seus trabalhadores, clientes atuais e potenciais, os meios de comunicação social, fornecedores, comunidade, entre outros (WALTON, 1974 apud VIEIRA, 1996, p. 4).

A maioria dos programas de qualidade de vida no trabalho tem sua origem em atividades de saúde e segurança. No entanto, QVT só começa a ter sentido à medida que deixa de ser restrita a programas internos de saúde 
ou lazer e passa a ter um sentido ampliado, que inclui a qualidade das relações de trabalho e as consequências na saúde, tanto das pessoas como da organização (VASCONCELOS, 2001).

Tais consequências para os colaboradores trazem implicações, também, para seu núcleo familiar. Isso porque "família" e "trabalho" podem ser considerados sistemas que o indivíduo permeia ao longo de sua vida. Assim, é preciso interligá-los para melhor esclarecer a relação entre interação familiar e a qualidade de vida no trabalho.

\subsubsection{Satisfação no trabalho}

A satisfação no trabalho influencia o trabalhador afetando sua saúde física e mental, sua atitude e comportamento tanto no lado profissional quanto social, repercutindo na vida pessoal e familiar do colaborador (MARTINEZ; PARAGUAY, 2003).

Os estudos sobre satisfação no trabalho tiveram seu início na década de 30 (KLIJN apud MARTINEZ; PARAGUAY, 2003) e, desde então, despertam o interesse de pesquisadores da área social, da saúde e da psicologia.

Sendo um fenômeno complexo, dependendo do olhar teórico adotado pelo autor, a satisfação no âmbito laboral será definida de diferentes formas. Para Fraser (1983 apud MARTINEZ, 2002), isso acontece porque essa é um estado pessoal e subjetivo, percebido pelo indivíduo. Assim, uma situação considerada importante para a satisfação de um colaborador pode não ser para o outro.

Conceitos mais utilizados são:

Satisfação no trabalho como sinônimo de motivação;

Satisfação no trabalho como atitude;

Satisfação versus insatisfação no trabalho;

Satisfação no trabalho como estado emocional (MARTINEZ; PARAGUAY, 2003).

Algumas abordagens teóricas selecionadas para tratar sobre o tema são:

Teoria da Hierarquia das Necessidades Humanas: Na década de 40 Maslow estruturou sua teoria, propondo que as necessidades humanas podem ser hierarquizadas em cinco níveis ascendentes: (1) necessidades fisiológicas - relacionadas à sobrevivência e ao equilíbrio do organismo; (2) necessidades de segurança - relacionadas à segurança física, emocional, familiar e social; (3) necessidades sociais - representadas pela vontade de interagir socialmente, pertencer, ser aceito e estimado por um grupo, necessidades de amizade e de amor; (4) necessidade de estima - necessidade do indivíduo em manter a autoesti- ma e ter a estima dos outros, desenvolver sentimentos de confiança, capacidade, valor, poder, prestígio, de ser necessário; (5) necessidades de autor realização - referentes ao autodesenvolvimento e à tendência dos indivíduos em tornar seus potenciais reais. À medida que as primeiras necessidades básicas são satisfeitas, as necessidades dos níveis seguintes surgem, até que se chegue às mais elevadas. Entretanto, essa hierarquia não é rígida, tais níveis podem ser interdependentes e justapostos. É possível inferir que o trabalho tem papel importante para o ser humano porque os aspectos psicossociais do trabalho podem favorecer ou dificultar a satisfação das necessidades.

Teoria da Satisfação no Trabalho de Locke: Foi desenvolvida por Locke, a partir dos anos 70 e tem seu fundamento na concomitância dos "valores", ou seja, na importância que o indivíduo confere à meta que almeja alcançar, e das "metas", ou objetivos desejados, que impulsionam e levam o indivíduo a agir, obtendo resultados que servirão como feedback para a atribuição dos valores. Locke considerou a satisfação no trabalho como uma relação entre o que o colaborador quer de seu trabalho e o que ele percebe que está obtendo. $\mathrm{O}$ trabalho seria, então, uma interação complexa de papéis, tarefas, responsabilidades, incentivos, recompensas e relações em um contexto físico e social. Assim, o entendimento da satisfação no trabalho demanda que o trabalho seja analisado em termos dos elementos que o constituem e a satisfação no trabalho global é o resultado da satisfação com variados elementos do trabalho. Mesmo existindo diferenças entre os colaboradores, existem semelhanças entre os fatores causais da satisfação no trabalho, pertencentes a dois grandes grupos: (a) eventos e condições - o trabalho em si e suas condições, o pagamento, possível promoção, reconhecimento, o ambiente de trabalho - e (b) agentes colegas e subordinados, supervisores e gerentes, empresa/ organização (MARTINEZ; PARAGUAY, 2003).

Após esses exemplos sobre teorias que envolvem satisfação no trabalho, é possível entender, de forma mais clara, tal tema. Porém, devido a sua subjetividade, é difícil encontrar padrões universais (SILVA apud MARTINEZ; PARAGUAY, 2003). É importante ressaltar que, apesar das respostas serem individuais, existe uma semelhança entre o que os colaboradores esperam de seu trabalho, permitindo que um determinado referencial teórico seja usado para estudos e pesquisas.

A saúde do colaborador tem sido associada à satisfação no trabalho, assim, indivíduos mais satisfeitos no 
âmbito laboral apresentam melhor qualidade de saúde e menor ocorrência de doenças. Além disso, a longevidade tem sido apontada como uma consequência. O nível de satisfação pode comprometer de forma positiva ou negativa o comportamento em relação a faltas, erros, rotatividade, acidentes de trabalho, por exemplo.

Como componente da vida, o trabalho pode comprometer a qualidade de vida do ser humano. Entretanto, isso não ocorre da mesma maneira para todos e dependerá de como o colaborador percebe as dificuldades do trabalho, suas gratificações, seu reconhecimento e como ele identifica o trabalho inserido em sua vida familiar e social.

\subsection{Família em interação com QVT}

Buscando iniciar a união dos temas "família" e "qualidade de vida no trabalho", aborda-se a teoria sistêmica.

Um sistema pode ser definido como um complexo de elementos em interação mútua. Esta definição pode ser aplicada para o indivíduo, para a família ou mesmo para a sociedade. Cada sistema pode se constituir de sub-sistemas e estar inserido em outros sistemas maiores (GA-

LERA; LUIS, 2002, p. 142).

Por esse olhar, a família pode ser entendida como um sistema fazendo parte de outro maior e sendo composto de muitos subsistemas, como a relação mãe-filho, o casal ou os irmãos. Ao mesmo tempo, a família faz parte de um suprassistema composto por vizinhos, escolas, igrejas, organizações, instituições de saúde, entre outros.

As fronteiras entre os sistemas são delimitadas de forma arbitrária e ajudam a estabelecer aqueles que estão dentro e fora do sistema familiar. Tais fronteiras auxiliam, ainda, a definir quais subsistemas e suprassistemas são importantes para a família em cada momento.

Um dos princípios da teoria de sistemas afirma que o todo é maior do que a soma de suas partes. Assim, a família é um todo maior do que a soma de seus membros. Com base neste princípio, a abordagem sistêmica se interessa pelas relações entre os diferentes sistemas e subsistemas presentes no sistema familiar para compreender melhor o funcionamento de cada um deles. As relações entre os membros do sistema familiar influenciam, de maneira significativa, os comportamentos, crenças e sentimentos de cada membro de uma família. Seguindo o princípio da circularidade, esses comportamentos, crenças e sentimentos influenciam, por sua vez, as relações entre os diferentes membros (GALERA; LUIS, 2002, p. 145).

Cardoso (2007) afirma que qualidade de vida é um conjunto de realizações, que devem acontecer em todos os níveis da vida do ser humano, como trabalho, saúde, lazer, família, entre outros. Esse conjunto necessita estar em equilíbrio e harmonia. Tal autora afirma, também, que a satisfação com o trabalho se encontra intimamente relacionada à satisfação com a vida em geral (CARDOSO apud VRENDENBURGH; SHERIDAN, 1979).

"Qualidade de vida no trabalho é o trabalho como qualidade de vida" (CARDOSO apud MATOS, 1996, p. 93).

Dessa forma, é possível entender os motivos que levam esta pesquisa a tomar vida. Tendo a imagem de todos os sistemas que compõem cada ser humano de forma holística (como família e trabalho, por exemplo), compreender como eles se relacionam e podem influenciar-se, mutuamente, é de suma importância.

\section{Análise}

O tripé qualidade de vida no trabalho, interação familiar e satisfação do colaborador foi o que formou a base para o trabalho, buscando entender como o contexto familiar e o ambiente laboral podem se influenciar.

Todos os seres humanos, quando nascem, se encontram em uma família, cada uma com sua constituição. Segundo José Filho (1998), é por meio dela que se passa ao mundo fora das paredes da casa, inserindo cada membro nas relações sociais. Assim, a família é de suma importância para todos, na medida em que fornece as bases iniciais para a constituição do ser em sua totalidade.

Outro papel importante da vida do ser humano é o de colaborador, funcionário ou trabalhador. $\mathrm{O}$ trabalho é um conjunto de atividades, um esforço feito pelos colaboradores com o intuito de atingir metas. Em cada emprego, desenvolvem-se habilidades, aprimoram-se conhecimentos, aprende-se a olhar para si e para o coletivo (empresa como um todo), além de contribuir para a satisfação pessoal e profissional.

Tais papéis do ser humano, membro de uma família ou de uma empresa, são exemplos dos vários sistemas que compõem a vida de cada um de nós. Como é descrito por Galera e Luis (2002), um sistema é entendido como um complexo de elementos em interação mútua.

Na busca de compreender a interação familiar em relação à qualidade de vida no trabalho, é preciso entender 
que os sistemas acabam por influenciar-se mutuamente. Assim, se um deles não está bem, não está adequado, o ser humano vai levar esse ponto negativo para o outro sistema. Com isso, se o colaborador não está adequado ao ambiente de trabalho, a família pode ser prejudicada em algum momento. De igual maneira, quando algo ocorre em casa, o trabalho pode ser afetado.

Para isso, a Tabela 1, a seguir, aborda a evolução do papel da mulher, do homem, da família e da qualidade de vida no trabalho:

TABELA 1: Comparativo da evolução dos papéis da mulher, do homem, da família e da QVT.

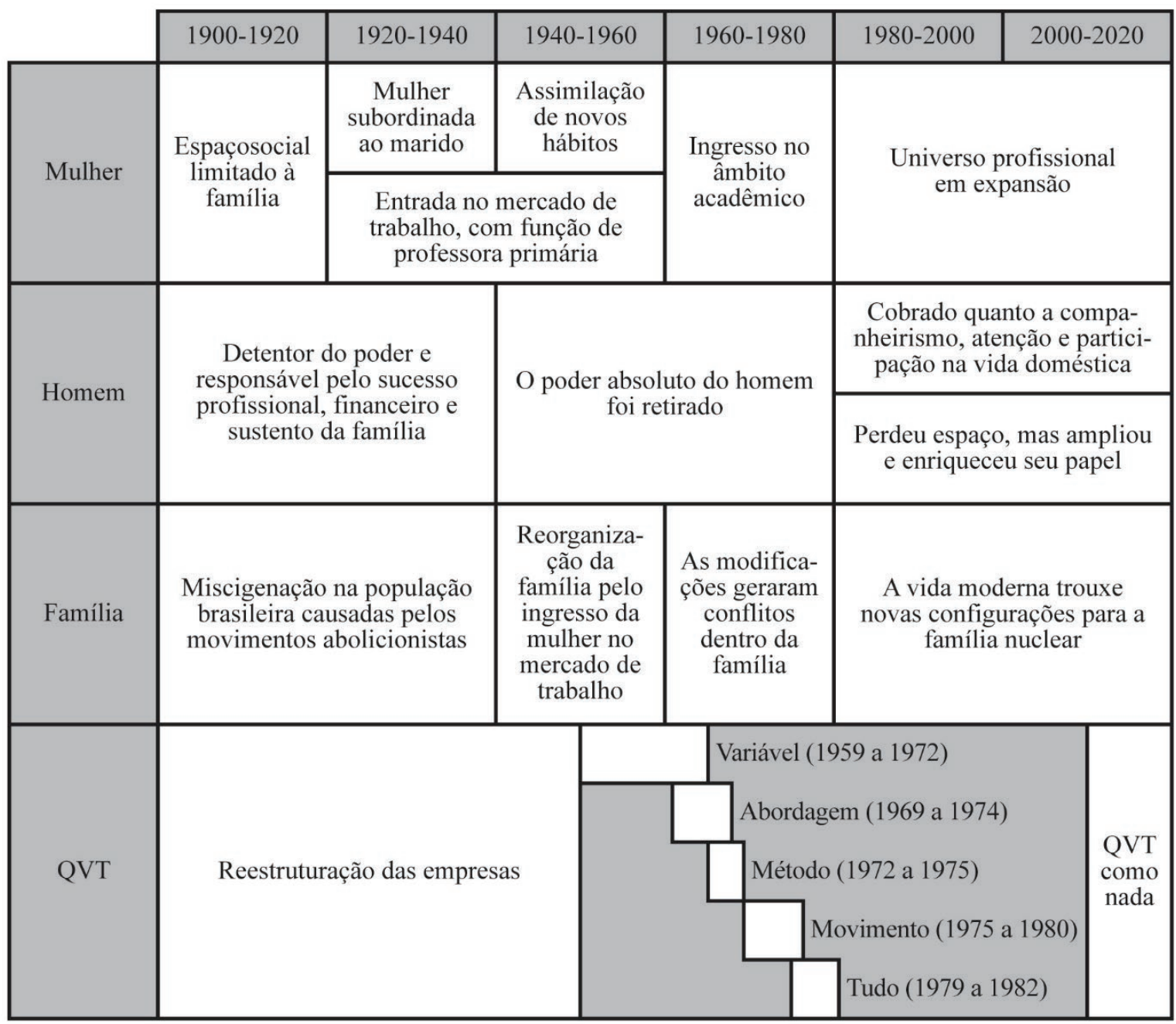

Fonte: elaborada pelo autor (2012)

Como descrito por Bertolini (2002), no início do século $\mathrm{XX}$, houve desequilíbrio entre os membros da família, o homem era um líder autoritário, a mulher era submissa às vontades do marido, os filhos seguiam o mesmo exemplo e a família vivia um momento de miscigenação. Já no âmbito laboral, Nadler \& Lawler (apud FERNANDES, 1996) afirmam que ocorria uma reestruturação nas empresas. Elas mudaram seus conceitos e modificaram suas práticas gerenciais.

Já a partir dos anos 40, houve uma assimilação de novos hábitos: a entrada da mulher no mercado de traba- lho e, como consequência, a perda do poder absoluto por parte do homem. Com o novo papel da mulher, aconteceu uma reorganização da família (BERTOLINI, 2002). No âmbito organizacional, as relações indivíduas versus trabalho versus organização passaram a ser estudadas e, nos anos 50, receberam o nome de qualidade de vida no trabalho (ARAÚJO, 2010).

É possível observar, então, que, enquanto a família estava se reorganizando, o trabalho se reestruturava. Quando a desigualdade na família começou a diminuir, uma nova visão começou a surgir no campo organizacional. 
Enquanto a família ainda se reorganizava, a qualidade de vida no trabalho ganhava novos pontos de vista. Começou uma investigação na busca da melhoria da qualidade de vida no trabalho para o colaborador. Algum tempo depois, o foco maior era no indivíduo, antes mesmo dos resultados da organização. Nesse meio tempo, um conjunto de métodos e técnicas foi ampliado para que o ambiente laboral fosse mais produtivo e satisfatório (NADLER; LAWLER apud FERNANDES, 1996).

Os conceitos de qualidade de vida no trabalho desenvolveram-se, juntamente ao conceito de família, que tem os papéis de seus membros se modificando, principalmente após a entrada da mulher no âmbito acadêmico, como afirma Bertolini (2002). No movimento QVT, era pregada uma administração participativa (NADLER; LAWLER apud FERNANDES, 1996).

É possível entender que quanto mais os papéis se equilibravam no meio familiar mais o âmbito laboral se equilibrava também. $\mathrm{O}$ universo profissional da mulher se expandiu, o homem participa da vida doméstica, enriquecendo seu papel dentro da família, contribuindo para a ocorrência de novas configurações na vida familiar (BERTOLINI, 2002). Ao mesmo tempo em que a qualidade de vida no trabalho ganha novas definições, como o atendimento de necessidades e aspirações dos colaboradores, abrangendo aspectos relacionados à participação desses nas decisões que lhes dizem respeito, sua orientação é em direção à humanização do trabalho, à democracia industrial, enfatizando-se a responsabilidade social de cada empresa (NADLER; LAWLER apud FERNANDES, 1996).

Para Walton (1974 apud VIEIRA, 1996, p. 4), as experiências no local de trabalho podem influir na vida pessoal e social dos colaboradores, tanto de maneira positiva como negativa. Ele recomenda um equilíbrio suficiente entre o trabalho dos colaboradores e as outras atividades existentes em sua vida, verificando sempre o nível de satisfação de cada um.

A satisfação no trabalho impulsiona a autoestima dos colaboradores e contribui para que o absenteísmo, as doenças laborais, os acidentes do trabalho e as aposentadorias precoces sejam reduzidos. Além disso, ocorre um aumento da efetividade da organização, contribuindo para a redução dos indicadores negativos, como erros, retrabalho, diminuição da produtividade, perda da qualidade nos serviços prestados, entre outros (MENDES, 2006).

Com a pesquisa, foi possível constatar que, ao lon- go do tempo, a mulher deixou de ter funções, exclusivamente, familiares e passou a disputar com o homem espaço no mercado de trabalho. Consequentemente, houve uma evolução nas atribuições de homens e mulheres no seio familiar. O espaço deixado pela mulher nos afazeres domésticos passou a ser preenchido pelo homem. Pode-se afirmar que, na atualidade, há equilíbrio de responsabilidades no âmbito das atividades domésticas e na criação e educação dos filhos.

A mulher deixa seu espaço dentro de casa e ocupa outro no local de trabalho, competindo de forma equilibrada com o homem. Eles atuam em cargos e funções iguais e muitas mulheres são líderes em suas empresas.

Com isso, o que ocorre em casa afeta tanto o homem quanto a mulher, pois, como ambos trabalham, acabam por estender as crises domésticas aos seus ambientes laborais, mesmo que involuntariamente. Da mesma maneira, os dois podem trazer resquícios do trabalho para a família.

Dessa forma, fica evidente a necessidade de um balanceamento entre todos os sistemas que compõem a vida do ser humano. Se algo não está adequado na vida profissional, o colaborador acabará transferindo o descontentamento para a família. Em contrapartida, se o âmbito familiar está com alguma dificuldade, sua produtividade no trabalho será afetada.

Entretanto, não está ao alcance da organização tudo o que acontece na família. Assim, é preciso investir no departamento de qualidade de vida no trabalho para que as dificuldades desnecessárias sejam eliminadas ou, pelo menos, diminuídas. Só assim o colaborador vai trabalhar com disposição, sentindo-se útil e valorizado por seus chefes. Isso, certamente, contribuirá para que esses colaboradores tenham prazer em chegar ao local de trabalho e, ao fim de suas jornadas, sintam-se realizados e levem isso para dentro de suas casas.

Assim, devem acontecer ações de qualidade de vida no trabalho que envolvam as necessidades familiares. Por exemplo, festa do Dia dos Pais, das Mães, das Crianças, convidando toda a família para o ambiente de trabalho. Dessa forma, cada membro sente-se inserido, também, naquele momento do colaborador. Os filhos, ao participarem de confraternizações na organização, conseguem entender melhor o que os pais fazem e por que precisam sair de casa para trabalhar. Além disso, essas atitudes da empresa promovem o acolhimento das famílias.

Como exemplo, é possível citar a empresa Philips 
do Brasil que foi eleita, no dia 5 de setembro de 2012, uma das "150 Melhores Empresas para Você Trabalhar", segundo o Guia Você S/A - Exame de 2012. Tal premiação é considerada um dos principais reconhecimentos da área corporativa no Brasil. Além disso, a Philips foi classificada como a melhor empresa na categoria Melhores Práticas de Saúde.

O presidente da empresa na América Latina, Henk de Jong, afirma que a Philips possui como missão melhorar a vida das pessoas por meio de inovações relevantes em saúde e bem-estar. E, para que isso seja uma verdade, a empresa busca começar essa missão melhorando a vida de seus colaboradores.

A empresa possui um programa chamado Vida Leve que estimula o equilíbrio da vida profissional e pessoal dos funcionários por meio de formas inovadoras de trabalho e benefícios com enfoque na saúde e no bem-estar. O equilibrar a vida profissional e pessoal é realizado com a vivência de momentos de lazer com a família e os amigos, cuidando do corpo e da mente. Para a Philips, isso é fundamental para a saúde de todos.

Para que isso ocorra no cotidiano, a empresa toma um conjunto de iniciativas em prol de seus colaboradores, baseadas na ideia de que saúde é mais que uma ausência de doença. A Philips oferece caminhos e investe em saúde e bem-estar, buscando a conquista de melhorias significativas para que o dia a dia seja mais agradável e produtivo.

\section{Considerações finais}

Os seres humanos nascem no seio de uma família, independentemente de sua constituição. E é ela que promove o começo da identidade das crianças e os introduz nas relações sociais. Como abordado, a família é o primeiro referencial de cada indivíduo e permeia toda sua existência. Dessa forma, fica clara a importância da família para todos.

Outro ponto importante da vida do ser humano é seu trabalho, entendido como um conjunto de atividades com o intuito de atingir metas. Em cada emprego, o funcionário desenvolve habilidades, aprimora conhecimentos, aprende a olhar para si e para o coletivo (empresa como um todo), além de contribuir para sua satisfação pessoal e profissional.

Como homens e mulheres trabalham, pode-se inferir que o que acontece no âmbito laboral afeta da mes- ma forma os dois. De igual maneira, ambos podem trazer resíduos do trabalho para seu lar.

Dessa forma, fica evidente a necessidade de um balanceamento entres todos os sistemas que compõem a vida do ser humano. Se algo não está adequado na vida profissional, o colaborador acabará transferindo o descontentamento para a família. Em contrapartida, se o âmbito familiar está com alguma dificuldade, sua produtividade no trabalho será afetada.

Assim, ficam explícitas a íntima relação e a mútua interferência existentes entre a interação familiar e a qualidade de vida no trabalho, ambas refletindo a satisfação do colaborador, independente do seu sexo.

Existem variados estudos que abordam o tema família e o tema qualidade de vida no trabalho. Entretanto, há uma carência em material bibliográfico que relacione os dois temas. Com isso, cabe aos futuros pesquisadores dar continuidade aos estudos dessa relação que se faz cada vez mais importante, buscando entender, por exemplo, como tal dualidade afeta as crianças; como famílias estruturadas ou desestruturadas interferem na economia; como programas de qualidade de vida no trabalho diminuem conflitos domésticos; entre tantos outros tópicos que ainda precisam ser mais bem estudados.

\section{Referências}

AGUIAR, Wanda Maria Junqueira. Reflexões a partir da psicologia sócio-histórica sobre a categoria consciência. Cadernos de Pesquisa, São Paulo, n. 110, p. 125-142, jul. 2000. Disponível em: <http://www.scielo.br/pdf/cp/ n110/n110a05.pdf>. Acesso em: 15 jun. 2012.

ARAÚJO, Tatiane Regina Petrillo Pires de. Estrutura e dinâmica de casais em grupos religiosos. 2011. Dissertação (Mestrado) - Programa de pós-graduação Stricto Sensu em Psicologia, 2011.

ARAÚJO, Tatiane Regina Petrillo Pires de. Origem e evolução dos estudos de qualidade de vida no trabalho. Brasília: UniCEUB, 2010.

BENINCÁ, Ciomara Ribeiro Silva; GOMES, Willian B. Relatos de mães sobre transformações familiares em três gerações. Estudos de Psicologia, Passo Fundo, v. 3, n. 2, p. 177-205, 1998. Disponível em: <http://www.scielo.br/ pdf/epsic/v3n2/a02v03n2.pdf>. Acesso em: 20 jun. 2012. 
BERTOLINI, Lucia Benatti de Almeida. Relações entre o trabalho da mulher e a dinâmica familiar. São Paulo: Vetor, 2002.

CARDOSO, Wilma Lucia Castro Diniz. Qualidade de vida e o trabalho: uma articulação possível. In: GUIMARAES, Liliana Andolpho Magalhaes; GRUBITS, Sonia. Saúde mental e trabalho. São Paulo: Casa do Psicólogo, 2007. p. 75-95. Disponível em: <http://books.google. com.br/books?hl=pt-BR\&lr=\&id=Ic_KYIH68y0C\&oi=fnd \&pg $=$ PA75\&dq=fam $\%$ C3\%ADlia + e + qualidade +de+vida+no+trabalho\&ots $=5 \mathrm{uuAj}_{3}$ _F $4 \&$ sig $=\mathrm{fKs}-$ 0NwXQ-YP-xW-p65xIlxUHDDI\#v=onepage $\& \mathrm{q}=$ fam $\%$ C3\%ADlia\%20e\%20qualidade\%20de\%20vida\%20no\%20 trabalho\&f=false $>$. Acesso em: 30 jul. 2012.

CHIAVENATO, Idalberto. Os novos desafios da gestão de pessoas. In: CHIAVENATO, Idalberto. Gestão de pessoas. Rio de Janeiro: Elsevier, 2004. Disponível em: <http://books.google.com.br/books?hl=p$\mathrm{t}-\mathrm{BR} \& \mathrm{lr}=\& \mathrm{id}=\mathrm{Uzs} Y 1 \mathrm{~A} 4 \mathrm{HXTIC} \& \mathrm{i}=\mathrm{f}$ d $\& p g=\mathrm{PR} 32 \& \mathrm{dq}=-$ hist\%C3\%B3rico+do+departamento+de+gest $\% \mathrm{C} 3 \% \mathrm{~A} 3 \mathrm{o}+-$ de+pessoas+recursos+humanos\&ots=OwL4UI8WGW\&sig=znEorxwegjwFSxplFskHzmBTrwI\#v=onepage\&q\&f=false >. Acesso em: 13 jun. 2012.

CRUZ, Tânia Cristina S.; LINS, Tatiana Barroso de Albuquerque. Normas para elaboração de monografias. Brasília: UniCEUB; ICPD, 2005.

FERNANDES, Eda. Qualidade de vida no trabalho: como medir para melhorar. Salvador: Casa da Qualidade, 1996.

GALERA, Sueli Aparecida Frari; LUIS, Margarita Antonia Villar. Principais conceitos da abordagem sistêmica em cuidados de enfermagem ao indivíduo e sua família. Rev Esc Enferm, São Paulo, v. 36, n. 2, p. 141-147, set. 2002. Disponível em: < http://www.scielo.br/pdf/reeusp/ v36n2/v36n2a05.pdf>. Acesso em: 25 jun. 2012.

GIL, Antonio Carlos. Como elaborar projetos de pesquisa. 5. ed. São Paulo: Atlas, 2010.

GIL, Antonio Carlos. Gestão de pessoas: enfoque nos papéis profissionais. São Paulo: Atlas, 2001.

GONÇALVES, Sandra Maria (Org). Família. Ide, São Paulo, n. 36, p. 3-37, 2002.
INSTITUTO BRASILEIRO DE GEOGRAFIA E ESTATÍSTICA. Disponível em: <www.ibge.gov.br>. Acesso em: 2 ago. 2010.

JOSÉ FILHO, Pe. M. A família como espaço privilegiado para a construção da cidadania. 1998. Tese (Doutorado) Programa de Pós-Graduação em Serviço Social, UNESP, Franca, 1998.

LIMONGI-FRANÇA, Ana Cristina; ARELLANO, Eliete Bernal. Qualidade de vida no trabalho. In: FLEURY, Maria Tereza Leme. As pessoas na organização. São Paulo: Gente, 2002. Disponível em: <http://books.google.com.br/books?hl=p$\mathrm{t}-\mathrm{BR} \& \mathrm{lr}=\& \mathrm{id}=\mathrm{Q} 8 \mathrm{~s}=5-\mathrm{GGj} 88 \mathrm{LC} \& \mathrm{oi}=$ fnd $\& \mathrm{pg}=\mathrm{P} 295 \mathrm{~A} \& \mathrm{dq}$ .+Limongi-Fran\%C3\%A7a+(1996)\&ots=mIrW0Fu3oi\&sig=U-HA6gyiip1jBR-54aazIkePshE\#v=onepage\&q=.\%20Limongi-Fran\%C3\%A7a\%20(1996)\&f=false >. Acesso em: 13 jun. 2012.

MARTINEZ, Maria Carmen. As relações entre a satisfação com aspectos psicossociais no trabalho e a saúde do trabalhador. 2002. 255 f. Dissertação (Mestrado em Saúde Ambiental) - Faculdade de Saúde Pública da Universidade de São Paulo, São Paulo, 2002. Disponível em: $<$ http://www.teses.usp.br/teses/disponiveis/6/6134/tde07112006-210400/publico/MartinezMC.pdf>. Acesso em: 8 out. 2012.

MARTINEZ, Maria Carmen; PARAGUAY, Ana Isabel Bruzzi Bezerra. Satisfação e saúde no trabalho: aspectos conceituais e metodológicos. Cadernos de Psicologia Social do Trabalho, São Paulo, v. 6, 2003. Disponível em: <http://www.revistasusp.sibi.usp.br/pdf/cpst/v6/v6a05. pdf>. Acesso em: 8 out. 2012.

MENDES, Ana Magnólia. Só de pensar em vir trabalhar, já fico de mau-humor: como implantar um programa de qualidade de vida no trabalho no serviço público. Brasília: UnB, 2006. Disponível em: <http://www.senado.gov. br/portaldoservidor/jornal/jornal69/PalestrasQualiVida/ AnaMagnoliaMendes.pdf>. Acesso em: 14 ago. 2012.

MINUCHIN, S.; FISHMAN, H. C. Ténicas de terapia familiar. Porto Alegre: Artes Médicas, 1990.

MINUCHIN, S. Família: funcionamento e tratamento. 2. ed. Porto Alegre: Artmed, 1982. 
NEVES, José Luis. Pesquisa qualitativa: características, usos e possibilidades. Caderno de Pesquisas em Administração, São Paulo, v. 1, n. 3, p. 1-5, 1996. Disponível em: <http://www.ead.fea.usp.br/cad-pesq/arquivos/C03art06.pdf>. Acesso em: 10 jul. 2012.

PHILIPS. Disponível em: <http://www.newscenter. philips.com/br_pt/standard/about/news/press/article-2012090601.wpd>. Acesso em: 8 out. 2012.

SILVA, Nancy Capretz Batista da et al. Variáveis da família e seu impacto sobre o desenvolvimento infantil. Temas de Psicologia, Ribeirão Preto, v. 16, n. 2, 2008. Disponível em: <http://www.sbponline.org.br/revista2/vol16n2/ v16n2a06t.htm>. Acesso em: 14 ago. 2012.
VASCONCELOS, Anselmo Ferreira. Qualidade de vida no trabalho: origem, evolução e perspectiva. Caderno de Pesquisas em Administração, São Paulo, v. 8, n. 1, p. 23-35. jan./mar. 2001. Disponível em: <http://www.luzimarteixeira.com.br/wp-content/uploads/2009/06/qualidade-de-vida-no-trabalho-origem.pdf $>$. Acesso em: 13 jun. 2012.

VIEIRA, Adriane. A qualidade de vida no trabalho e o controle da qualidade total. Florianópolis: Insular, 1996. 